\title{
Standardization of leaf age for radical scavenging activity in Terminalia arjuna
}

\author{
Ranjan P. Kuvad, Kiran S. Chudasama, Vibhuti M. Jhala and Vrinda S. Thaker* \\ Centre for Advanced Studies in Plant Biotechnology and Genetic Engineering, Department of Biosciences, \\ Saurashtra University, Rajkot (Gujarat), INDIA \\ *Corresponding author. E-mail: casprogramme@gmail.com
}

Received: August 30, 2013; Revised received: February 25, 2014; Accepted; March 21, 2014

\begin{abstract}
Terminalia arjuna is one of the many such plant that used in indigenous system of medicine for curing different diseases. For effective formulation of herbal drug selection of proper age of the plant is imperative. In the present study, the $T$. arjuna plant (leaves) was collected from the Botanical garden of Saurashtra University. The leaves were grouped in to various size and growth analysis was performed. Each extract homogenized in methanol and was used for chlorophyll estimation and antioxidant activities. Radical scavenging activity of the methanol extract of different stages leaves were determined using a stable free radical 2, 2-diphenyl-1-picryl hydrazyl (DPPH), using Micro plate assay. Further the phenolic compounds were separated by Reverse phase high pressure liquid chromatography analysis (RP-HPLC). At the leaf stage when maximum antioxidant activity was observed, phenol like Gallic acid showed distinct peak. The role of phenolic compounds in antioxidant activities is discussed.
\end{abstract}

Keywords : Antioxidant activity, Chlorophyll content, Growth, Terminalia arjuna

\section{INTRODUCTION}

Natural products, especially plants, have been used for the treatment of various diseases for dates as far back as 60,000 years ago in both developed and undeveloped countries (Solecki, 1975; Kaur et al., 2011). Over the centuries, the use of medicinal plant has become an important part of daily life despite the progress in modern medical and pharmaceuticals research. Plants have ability to synthesize a wide variety of biologically functional compounds, e.g. primary and secondary metabolites. Many of these phytochemicals $(12,000$ such compounds $)$ have beneficial effects on long-term health when consumed by humans, and can be used to effectively treat human diseases (Tapsell et al., 2006). However, the effectiveness of the aurvedic formulation is questioned many times or it has reported slow responses. Applications of these compounds for pharmaceutical preparations require a proper selection of plant materials. The desired compound may not have required concentration throughout the growth and development time of the plant part use. Most of the phytochemical studies concentrated on leaves and the constituents vary depending upon the geographical distribution (Chong and Aziz, 2011). Therefore, it is imperative to investigate the appropriate age of the plant for better and effective drug formulation.

Terminalia arjuna belongs to family Apiaceae (Umbelliferae) and is used as a natural source of medicine for long time. Many compounds are isolated from the different parts like bark, leaves and fruits of arjuna have been used in indigenous system of medicine for different ailments (Warrier et al., 1996). It has been considered by the modern practitioners as a cardiactonic (Dwivedi, 2007). Clinical evaluation of this botanical medicine indicates that it is beneficial in the treatment of coronary artery disease, heart failure and possibly antibacterial, antioxidant, antimutagenic and hepatoprotective activities (Kaur et al., 2002; Subasini et al., 2007). Leaves also serve as a remedy for the treatment of ear ache (Khory, 1867). Medicinal plants containing active chemical constituents with high antioxidants property play an important role in the prevention of various degenerative diseases (Lukmanul et al., 2008). T. arjuna leaves are an important source of antioxidants (Bhalodi, 2004). There seems to be no report on the relationship with the age/size of the leaf and antioxidant potential.Considering to this in presents study, the chlorophyll content, antioxidant potential was estimated with growth of $T$. arjuna leaves. An attempt has also been made to standardize the leaf age of $T$. arjuna along with the separation of phenolic compounds.

\section{MATERIALS AND METHODS}

Collection of plant material: Terminalia arjuna leaves where collected from the Botanical Garden of Saurashtra University campus, Rajkot, Gujarat. It was separated in 12 groups as per their smaller to larger size. The smaller leaf was about $20 \mathrm{~mm}^{2}$ and the larger one was $3000 \mathrm{~mm}^{2}$. Each leaf was sized and weight individually and grouped showed nearly similar data $( \pm 0.1 \%$ to $0.43 \%)$, are clubbed and numbered from 1 - 12 according to their increasing size. 
Identification and confirmation of the sample: The plant was authenticated by Prof. Vrinda Thaker, Department of Biosciences, Saurashtra University and Voucher specimen (CPBGE -110) is deposited in the herbarium of same Department.

Preparation of leaves extract: Each group of leaves from $20 \mathrm{~mm}^{2}$ to $3000 \mathrm{~mm}^{2}$ (Figure) was collected from the garden. Each leaf was washed under running tap water several times and rinses with distilled water. It was dried over blotting paper and $500 \mathrm{mg}$ sample was homogenized with a mortar and pestle containing of 10 $\mathrm{ml}$ of $80 \%$ methanol. The samples were centrifuged at $10,000 \mathrm{~g}$ for $10 \mathrm{~min}$ and supernatant was collected. The pellet was washed with $80 \%$ methanol till it was free from the chlorophyll pigments. The supernatants were pooled and used for the estimation of chlorophyll and antioxidant activity. In our preliminary assay with 100-1500 mg sample size, $500 \mathrm{mg}$ was adequate.

Growth analysis: Growth was measured in the terms of fresh weight, dry weight, water content and leaf area. For the measurement of fresh and dry weights, freshly harvested smaller to larger sized of leaves were taken. Freshly separated leaves were weighed before and after oven drying to a constant weight at $65{ }^{\circ} \mathrm{C}$ for 48 hours to obtain the data on fresh and dry weights. Water content of each stage was determined by difference in fresh and dry weight. For each data point, three replicates were taken and mean value of dry weight and water content was calculated.

Leaf area and chlorophyll measurements: Leaf area was measured by Leaf area meter software Muchhadia and Thaker (2006). Chlorophyll content was determined according to Arnon (1949) using Spectrophotometer. Data for chlorophyll a and $\mathrm{b}$ were recorded at 645 and $663 \mathrm{~nm}$ respectively.

DPPH free radical scavenging assay: Radical scavenging assay was determined according to Velázquez et al. (2003) using DPPH (1,1-diphenyl-2picryl hydrezyl) free radical scavenging assay and color change from purple to yellow, which was measured on Microplate reader ( $\mu$ Quant, Bio Teak, USA).

Reverse phase high pressure liquid chromatography analysis (RP-HPLC): Reverse phase chromatography analyses were carried out under gradient condition using a Luna C-18 column $(4.6 \times 250 \mathrm{~mm})$ packed with $5 \mu \mathrm{m}$ diameter particles. The mobile phase was solvent $\mathrm{A}\left(0.2 \% \mathrm{H}_{3} \mathrm{PO}_{4}\right.$ in milli $\left.\mathrm{Q}\right)$ and solvent $\mathrm{B}$ $\left(0.2 \% \mathrm{H}_{3} \mathrm{PO}_{4}\right.$ in methanol).

The gradient program was started with $90 \% \mathrm{~A}$ and $10 \% \mathrm{~B} ; 0-1 \mathrm{~min}, 25 \% \mathrm{~A}$ and $75 \% \mathrm{~B} ; 1-65 \mathrm{~min}, 0 \% \mathrm{~A}$ and $100 \% \mathrm{~B}$; $66-95 \mathrm{~min} .100 \% \mathrm{~A}$ and $0 \% \mathrm{~B} ; 96-100$ min., 90\% A and 100\% B; 100-120 min. respectively. The flow rate was $1 \mathrm{ml} / \mathrm{min}$. and the injection volume was $20 \mu \mathrm{l}$. The temperature of column was controlled at $28{ }^{\circ} \mathrm{C}$. The detection wavelength of (Photodiode Array Detector) PDA was set at $290 \mathrm{~nm}$. Prior to each run, the HPLC-PDA system was allowed to warm and the baseline was monitored until it was stable before sample analysis. Data were obtained by Shimadzu class LC solution software and the results were obtained by comparison with the standard.

Statistical analysis: Experimental data was analyzed using analysis of variance (ANOVA) and significant difference among means from triplicate analyses at $(\mathrm{P}<0.05)$ were determined.

\section{RESULTS AND DISCUSSION}

The study conducted for growth, chlorophyll contents and antioxidant activities were selected from the categories of the leaf collections from $1^{\text {st }}$ to last $12^{\text {th }}$ stages and relationship with these parameters was worked out. Growth parameters by way of the physical parameters of fresh and dry weight, water content and leaf area measurements are shown in Figs. $1 \mathrm{~A}$ and 2. Fresh weight in first stage was recorded to be $0.02 \mathrm{gm}$ and then increased with different leaf up to $5.56 \mathrm{gm}$ at mature stage. Maximum fresh weight was observed in $12^{\text {th }}$ stage and minimum was recorded in the $1^{\text {st }}$ stage (Fig.1A). Similarly, dry weight in the first stage was recorded to be $0.01 \mathrm{gm}$ which increased with different leaf up to $2.31 \mathrm{gm}$ the in last stage. Maximum dry weight was observed in the $12^{\text {th }}$ stage and minimum in the $1^{\text {st }}$ stage (Fig. 1B). Water content in first stage was $0.01 \mathrm{gm}$ and then increased with different leaf up to $3.25 \mathrm{gm}$ in last stage. Maximum water content was observed in the $12^{\text {th }}$ stage and minimum in $1^{\text {st }}$ stage (Fig. 1C).

The statistical analysis of these parameters showed that fresh weight and dry weight of the leaves showed highly significance $(\mathrm{P}<0.05)$. Since the fresh weight and dry weights showed close correlation, the water content also showed significant relationship $(\mathrm{P}<0.01)$. A number of the studies have shown that water content plays an important role in increase in the size of cotton fiber (Gokani and Thaker, 2001), cotton seed (Rabadia et al., 1999) and internodes development (Patel and Thaker, 2007).

Leaf area in the first stage $20 \mathrm{~mm}^{2}$ and then gradually increased with different leaf up to $3000 \mathrm{~mm}^{2}$. Maximum leaf area was recorded in the $12^{\text {th }}$ stage and minimum in the $1^{\text {st }}$ stage (Fig. 2). It was observed that the area count by the software was accurate and less time consuming in contrast to conventional methods. Leaf area showed more relation with fresh weight, followed by dry weight and water content, respectively. Chlorophyll a content was gradually increased with the different size of the leaf. Chlorophyll content in first stage was $0.0036 \mathrm{mg}$ and then increased up to $2.5 \mathrm{mg}$ in last stage. Maximum chlorophyll was observed in the $12^{\text {th }}$ stage and minimum in the $1^{\text {st }}$ stage (Fig. 3D). Chlorophyll-b content was also increased in first stage $0.012 \mathrm{mg}$ up to $8 \mathrm{mg}$. Maximum chlorophyll was observed in the $12^{\text {th }}$ stage and minimum in the $1^{\text {st }}$ stage of leaf (Fig. 1E). Total chlorophyll content was in initial stage 0.0065 $\mathrm{mg}$ and in last stage of leaf $3.6 \mathrm{mg}$. Maximum total chlorophyll content was in the $12^{\text {th }}$ stage of leaf and minimum in the $1^{\text {st }}$ stage of leaf (Fig.1F). Chlorophyll contents showed closed relationship with leaf area $(\mathrm{P}<$ 


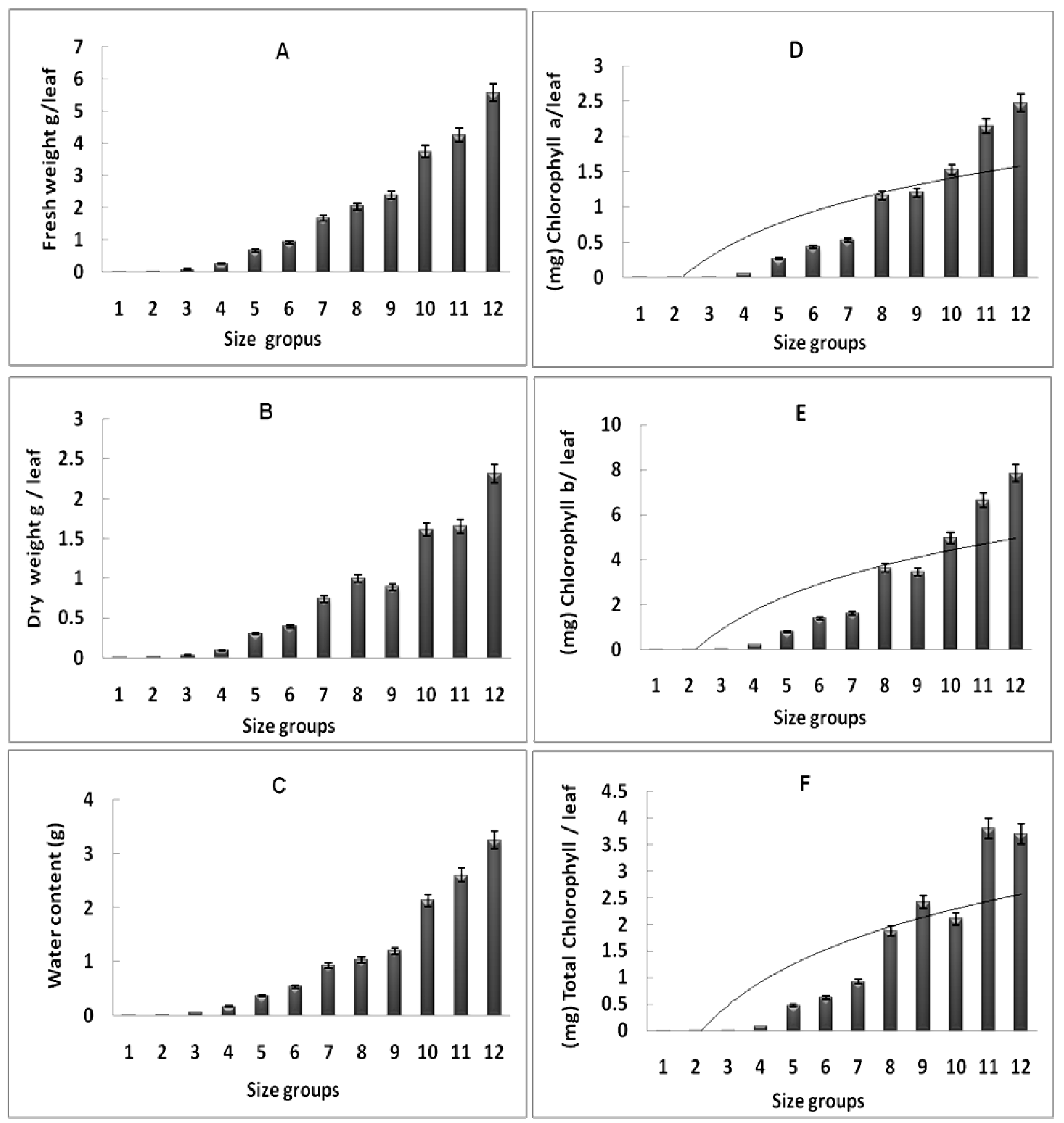

Fig. 1. Changes in (A) Fresh weight (B) Dry weight $(C)$ Water content (D) Chlorophyll a (E) Chlorophyll b $(F)$ Total Chlorophyll content in leaf of $T$. arjuna against size group.

$0.01)$, followed by dry weight $(\mathrm{P}<0.01)$ and water content $(\mathrm{P}<0.01)$.

Radical scavenging activity was measured in $\mu \mathrm{g}$ equivalent to ascorbic acid per mg of fresh weight. The remarkable activity was observed at the $1^{\text {st }}$ stage 1.21 $\mu \mathrm{g}$ up to the $4^{\text {th }}$ stage and then declined, again slowly increased up to last stage of leaf. Maximum free radical scavenging activity was observed in the $12^{\text {th }}$ stage and minimum in the $1^{\text {st }}$ stage of leaf (Fig. 3). The maximum significant relationship of antioxidant activities and chlorophyll contents leaf area was observed ( $\mathrm{P}<0.01)$ with total chlorophyll, chlorophyll a and chlorophyll b. It was followed by leaf area $(\mathrm{P}<$ $0.02)$, fresh and dry weights, and water content $(\mathrm{P}$
<0.05). In fact, the ratio of unit leaf area and the antioxidant activities remained higher at the stage 3 and 4. Since the maximum activity was recorded at the $12^{\text {th }}$ stage, the data were further analyzed for the HPLC separation of phenols.

In the RP-HPLC analysis, the Gallic acid was detected to be 1.4 min which matched the retention time of standard library of the instrument used (Fig. 4). These results suggest that the Gallic acid may have role in the antioxidant potential of the leaf in Arjuna. In number of the studies, it is reported that the antioxidant properties of herbal material are of a great value for the pharmaceutical properties. It is used in antiathersclerotic activity (Ram et al., 1997), antibacterial activity 


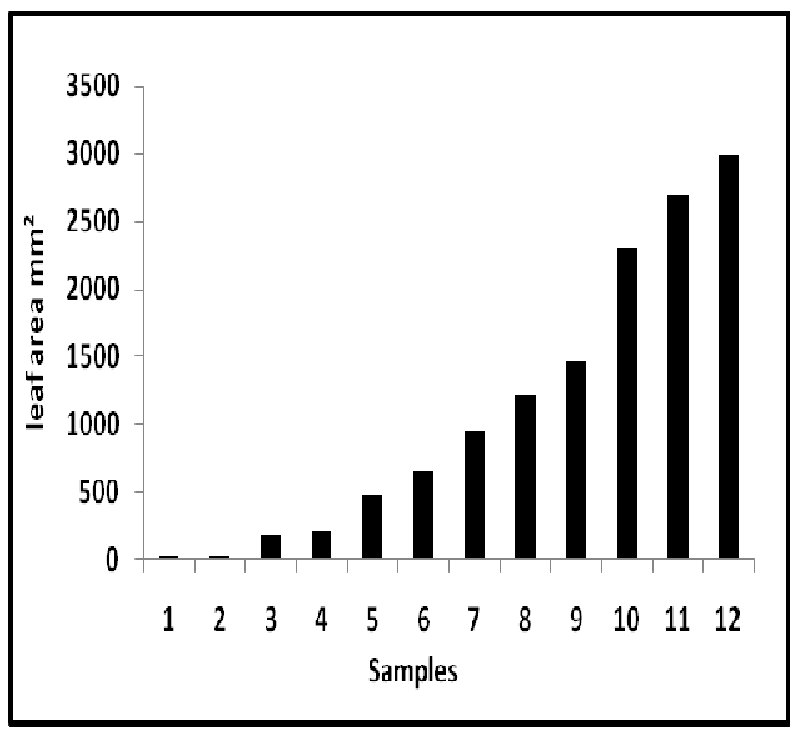

Fig. 2. Leaf area measurement of $T$. arjuna against size group.

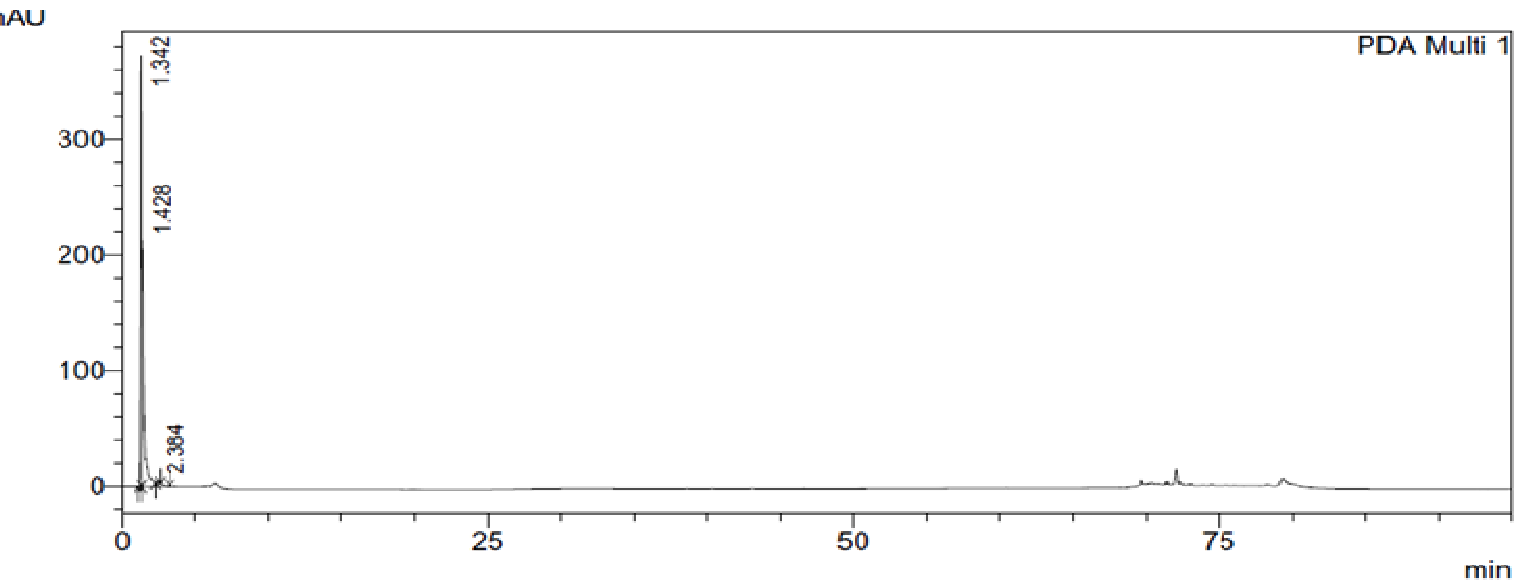

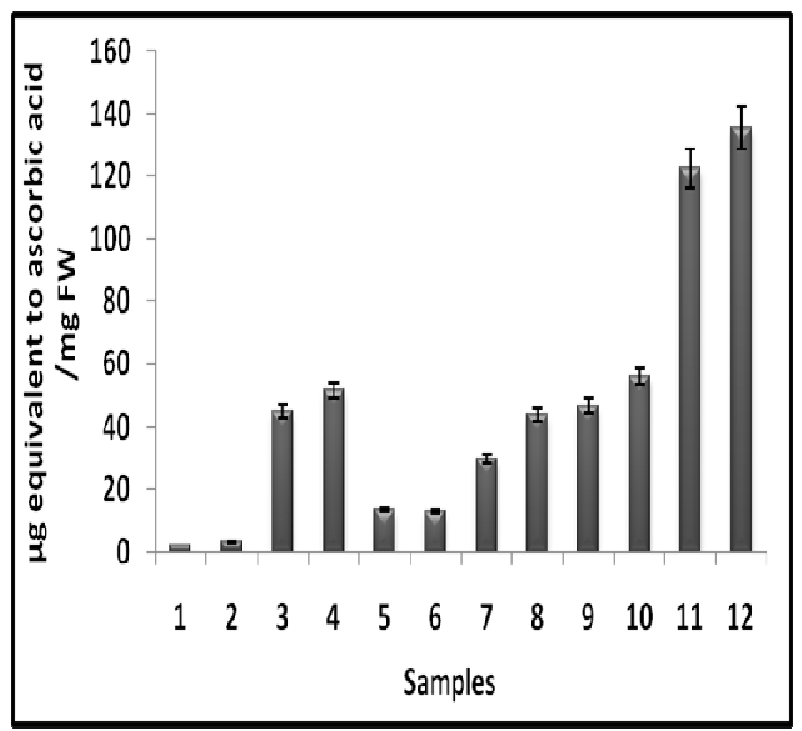

Fig. 3. Changes in Antioxidant activity of T. arjuna against size group.

Fig. 4. RP-HPLC analysis of Terminalia arjuna extract.

(Kaur et al., 2002), antiviral activity (Cheng et al., 2002), antioxidant activity (Bhalodi, 2004), wound healing activity (Chaudhari and Mengi, 2006), antidiabetic activity (Raghavan and Kumari, 2006), cardiovascular activity (Dwivedi, 2007), gastric activity (Devi et al., 2007), hepatoprotective activity (Subasini et al., 2007), antitumor activity (Reddy et al., 2008), reproductive activity (Manna et al., 2008), antiinflammatory activity, immunomodulatory activity and antinociceptive activity (Halder et el., 2009). The increase of phytochemicals, which act as antioxidants, can help to optimize human diet with health benefit by reducing oxidative damage in the cell (Mohanty and Cock, 2012).

\section{Conclusion}

It was concluded that different groups of $T$. arjuna have different potential for antioxidant and phenolic activities. However, growth parameters and chlorophyll content showed increasing trend. Further, the combination of growth and chlorophyll content may be used as criteria for leaf material selection in T. arjuna. 
chemical constituents of Centella asiatica. Research Journal of Pharmaceutical, Biological and Chemical Sciences, 2(3): 445-459.

Devi, R., Narayan, S., Vani, G., Srinivasan, P., Mohan, K., Sabitha, K. and Devi, C. (2007). Ulcer protective effect of Terminalia arjuna on gastric mucosal defensive mechanism in experimental rats. Phytotherapy $R e$ search, 21:762-767.

Dwivedi, S.V. (2007). Terminalia arjuna Weight and Arn. a useful drug for cardiovascular disorders. Journal of Ethnopharmacology, 114(2):114-129.

Gokani, S.J. and Thaker, V.S.(2001). Accumulation of abscisic acid in cotton fiber and seed of normal and abnormal bolls. Journal of Agriculture Science, 137:444-451.

Halder, S., Bharal, S.N., Mediratta, P.K., Kaur, I. and Sharma, K.K. (2009). Anti-inflammatory, immunomodulatory and antinociceptive activity of Terminalia arjuna bark powder in mice and rats. Indian Journal of Experimental Biology, 47:577-583.

Kaur, K., Arora, S., Kumar, S. and Nagpala, A. (2002). Antimutagenic activities of acetone and methanol fractions of Terminalia arjuna. Food Chemical Toxicology, 40:1475-1482.

Kaur, R., Kapoor, K. and Kaur, H. (2011). Plants as a source of anticancer agents. J. Natural Product Plant Resource, 1(1):119-124.

Khory, R.N. (1867). The Bombay material medica and their therapeutics. Renina's Union Press.

Lukmanul, F., Girija, A. and Boopathy, R. (2008). Antioxidant property of selected ocimum species and their secondary metabolite content. Journal of Medicinal plants, 2(9):250-257.

Manna, P., Sinha, P.M. and Sil, P.C. (2008). Protection of arsenic induced testicular oxidative stress by arjunolic acid. Redox Report, 13:67-77.

Mohanty, S. and Cock, I.E. (2012). The chemotherapeutic potential of Terminalia ferdinandiana Phytochemistry and Bioactivity. Pharmacognosy reviews, 6(11): 29-36.
Muchadia, and Thaker, V.S. (2006). Leaf area meter software ${ }^{\circledR}$. M.sc.Dissertation, Department of Bioscience, Saurashtra University, Rajkot.

Patel, D. and Thaker V. (2007). Role of cellwall stiffening enzymes in internodes development of Merremia emarginata. General and Applied Plant Physiology, 33(1-2):25-39.

Rabadia, V.S., Thaker, V.S. and Singh, Y.D. (1999). Relationship between water content and growth of seed and fiber of three cotton genotypes. Journal of Agriculture Crop Science, 183:255-261.

Raghavan, B. and Kumari, S.K. (2006). Effect of Terminalia arjuna stem bark on antioxidant status in liver and kidney of alloxan diabetic rats. Indian Journal of Physiology and Pharmacology, 50:133-142.

Ram, A. P., Lauria, R., Gupta, P., Kumar, P. and Sharma V.N.(1997). Hypocholesterolaemic effects of Terminalia arjuna tree bark. Journal of Ethnopharmacolog, 55(3):165-169.

Reddy, T.K., Seshadri, P., Reddy, K., Jagetia, J.C. and Reddy, C.D. (2008). Effect of Terminalia arjuna extract on adriamycin induced DNA damage. Phytotherapy Research, 22:1188-1194.

Solecki, R.S. (1975). Shanidar IV a neanderthal flower burial of Northern Iraq. Science, 190(28):880-881.

Subasini, U., Rajamanickam, G.V., Dubey, G.P., Prabu, P.C. and Sahayam, C.S. (2007). Hydroalcoholic extract of Terminalia arjuna: A potential hepatoprotective herb. Journal of Biological Sciences, 7:255-262.

Tapsell, L.C., Hemphill, I. and Cabiac, L. (2006). Health benefits of herbs and species: the past, the present the future. Medical Journal of Australia, 185:24-54.

Velázquez, E., Tournier, H.A., Mordujovich de Buschiazzo, N., Saavedra, G. and Schinella, G.R. (2003). Antioxidant activity of Paraguayan plant extracts. Fitoterapia, 74:91-97.

Warrier, P.K., Nambiar, V.P. and Kutty C.B. (1996). Indian Medicinal plants. A Compendium of 500 species. Vol.1, Orient longman Pvt. Ltd., Madras, India. 